Escritura e Imagen

ISSN: $1885-5687$

http://dx.doi.org/10.5209/ESIM.62766

\title{
Literaturas de la pena de muerte o Hugo contra Kant. Para una deconstrucción del hombre
}

Delmiro Rocha

Recibido: 16 de junio de 2018 / Aceptado: 25 de julio de 2018

Resumen. A partir del Séminaire La peine de mort de Jacques Derrida, el artículo centra su atención en aquello que la literatura de la pena de muerte ha excluido. Poniendo a dialogar el abolicionismo de Hugo con el anti-abolicionismo de Kant, el texto escribe una interpretación de ese diálogo desde cierta violencia sexual. Se trata de pensar qué ocurriría si preguntásemos: ¿es la pena de muerte lo propio de la mujer?

Palabras clave: mujer; deconstrucción; exclusión; pena de muerte; dignidad.

\section{[en] Literatures of the death penalty, or Hugo against Kant. For a deconstruction of man}

\begin{abstract}
Based on Séminaire La peine de mort of Jacques Derrida, the article focuses on what the literature on the death penalty has excluded. Putting to dialogue the abolitionism of Hugo with the antiabolitionism of Kant, the text writes an interpretation of that dialogue from certain sexual violence. It is about thinking what would happen if we ask: is the death penalty the woman's own?
\end{abstract}

Keywords: woman, deconstruction, exclusion, death penalty, dignity.

Cómo citar: Rocha, D. (2018) "Literaturas de la pena de muerte o Hugo contra Kant. Para una deconstrucción del hombre", en Escritura e Imagen 14, 123-132. 
Dios crea al hombre a Su propia imagen - Se da dominio al hombre sobre todas las cosas, y se le manda multiplicarse y henchir la tierra. (Génesis, I)

¿Qué responder a alguien que viniese a decirles, al alba: “saben ustedes, la pena de muerte es lo propio del hombre”? (Derrida, J., Seminario La pena de muerte)

Nos proponemos acercarnos a esta pregunta, la primera pregunta y también la primera frase del Séminaire La peine de mort de Jacques Derrida - ¿Qué responder a alguien que viniese a decirles, al alba: «saben ustedes, la pena de muerte es lo propio del hombre»? ${ }^{1 "}$-, desde cierto ángulo, al menos uno, de la cuestión de la diferencia sexual. Se trata de pensar qué podría ocurrir si el seminario empezase así: "¿Qué responder a alguien que viniese a decirles, al alba: «saben ustedes, la pena de muerte es lo propio de la mujer»?". Si hubiese tal cosa, ¿nos mostraría su historia literaria una pena sustancialmente distinta de la pena del hombre? Es decir, ¿lo propio de la mujer se vincularía de diferente modo con la así llamada pena de muerte? Y, ¿cuál sería ese vínculo?, ¿en qué consistiría esa relación, esa relación de muerte, esa relación con la muerte que pone fin a todo vínculo posible?, y ¿cómo definir la exclusión y la autonomía en esa relación?, ¿qué significa, en definitiva, que la pena de muerte sea lo propio del hombre?

Veremos reaparecer, en nombre de todos los aparecidos que tejen estas líneas, en nombre de las desaparecidas, de todas aquellas que no dejan de desaparecer bajo alguna modalidad de la muerte, de las penas de muerte, al amparo de las leyes o contra ellas, por mor de ciertas exclusiones teológico-jurídicas, veremos reaparecer estas exclusiones y autonomías, así como la exclusión de la autonomía, al intentar acercarnos de otro modo a la pena de muerte, a la pena de la pena de muerte y a la muerte de la pena de muerte, cruzando dos posturas, dos argumentaciones, una de Victor Hugo y otra de Kant. Dos personajes que forman parte fundamental del seminario de Derrida sobre la pena de muerte, pero intentaremos acercarnos de otro modo a ellos y los forzaremos a cruzar sus argumentos. Nos situamos, pues, en una, al menos una, de las múltiples puertas abiertas que el seminario nos deja para plantear la cuestión de la exclusión, de la violencia de la exclusión, de la exclusión violenta, a veces piadosa, como en Hugo, y plantear la posibilidad de un fondo de violencia sexual como base de la exclusión.

Está en juego también el uso reduccionista que la violencia de la gramática ha reservado largo tiempo, y reserva todavía, a la palabra "hombre", al uso cotidiano y generalizado de la palabra "hombre", así como al uso filosófico y general de la palabra "hombre". Aquí el problema no se resuelve duplicando a cada paso el género de los vocablos, incluso si el gesto viene cargado de buenas intenciones. O precisamente porque está cargado de buenas intenciones. Sea como fuere, aquí se propone, antes bien, una deconstrucción del hombre, una deconstrucción no reducible a la gramática, aunque atravesada por ella, que solicitaría, haría temblar y tambalear los cimientos mismos de la comprensión del hombre, de la palabra "hombre" y de lo propio del hombre. Esta es sin duda una de esas deconstrucciones infinitas que Derrida ha puesto en marcha en sus textos y en la cual profundiza en su seminario sobre la pena 
de muerte. Sin embargo, no podemos entender la deconstrucción del hombre como un paso previo para la reflexión o para una deconstrucción determinada porque toda deconstrucción es determinada, aquí y ahora, y es ya siempre una deconstrucción del hombre, de lo propio del hombre, también de la palabra "hombre", de ese propio del hombre que encierra y posibilita la historia de las exclusiones, también, entonces, esa historia de la exclusión de la mujer y su exclusión de la historia. Por eso nos situamos aquí en su interior y pretendemos fijarnos, desde apenas algunas líneas de Hugo y Kant, en otro uso reduccionista y violento, excluyente, y veremos que esta exclusión tiene varias lecturas posibles, como mínimo la benévola y la perversa. Desde el interior de la deconstrucción de lo propio del hombre pretendemos fijarnos, pues, en ese uso ejercido por la máquina de dar muerte legal contra los hombres como cuerpos sexuados.

¿Se puede hablar de una violencia sexual de la pena de muerte? A este respecto podríamos analizar algunas estadísticas ${ }^{2}$ que muestran claramente cómo la pena capital se ha ejercido, y se ejerce, principalmente sobre individuos de sexo masculino, sobre el hombre, por así decirlo. Y si seguimos a Kant, esta violencia sexual sería, otra vez, una muestra de violencia de género, pues lejos de proteger a la mujer de la muerte, lo que hace es prohibirle su privilegio. En efecto, según la interpretación kantiana de la justicia, de la dignidad de la justicia, dignidad de la que Kant decía que hace hombre al hombre, semejante interpretación consiste en ser capaz de situarse por encima de la vida terrenal, animal, y aceptar la pena de muerte como el resorte necesario para acceder a aquello que está por encima de cualquier individuo, para acceder a la dignidad humana y a la justicia. Si podemos permitirnos usar de este modo la lógica kantiana diremos que la violencia de la máquina de matar legalmente, lejos pues de proteger a la mujer, consigue alejarla de la idea de la responsabilidad, que solo residiría, en última instancia, en el hombre, en los hombres, lejos de protegerla, pues, consigue privarla del acceso a la justicia y a la dignidad humana.

El propio Victor Hugo, en sus apasionados discursos a favor de la abolición de la pena de muerte, reserva un espacio diferenciado para la figura de la mujer, para la figura antes que para la mujer.

Se plantea una cuestión espantosa.

Una mujer llamada...-¿qué importa el nombre?- Una mujer ha sido condenada a muerte. ¿Por quién?

¿Por una sala de lo penal? - Es muy sencillo. Guillotínenla.

No. ¿Por un consejo de guerra? - Pues bien, fusílenla.

En efecto, el consejo de guerra no dispone de guillotina.

Ahora, examinemos lo siguiente.

¿Fusilar a una mujer?

Fusilar a un hombre se entiende. De hombre a hombre esas cosas se hacen. Está dentro del orden, no dentro del orden natural sino del orden social.

¡Pero fusilar a una mujer!

Fusilarla fría, oficial, reglamentariamente.

\footnotetext{
2 El proyecto interuniversitario "Nomes e voces", desarrollado por la Universidad de Santiago de Compostela en colaboración con la Universidad de Vigo y la Universidad de A Coruña, en su "informe de resultados: Galicia (1936-1939)", recoge que de todas las penas de muerte ejecutadas durante ese periodo el $99.4 \%$ fueron aplicadas a hombres y el $0.6 \%$ a mujeres. Los datos están publicados en la web: www.nomesevoces.net
} 
¿Nos imaginamos algo así?

Doce hombres, doce hombres jóvenes, ayer campesinos, hoy soldados, ayer inocentes en su pueblo, mañana quizá sublimes en el campo de batalla, doce valientes corazones, doce almas jóvenes, doce ciudadanos como ustedes y como yo caen por sorteo, el azar los elige $\mathrm{y}$, de pronto, se convierten en ejecutores.

¿Ejecutores de quién?

No acuso a la ley, no acuso al tribunal; la ley es inconsciente, el tribunal es honesto. Simplemente constato los hechos.

Llevamos a estos doce buenos chicos ante un poste, a ese poste se ata a alguien, y se les dice: dispárenle.

Miran y ven a una mujer.

Ven una frente que les recuerda a su hermana; ven un seno que les recuerda a su prometida; ven un vientre que les recuerda a su madre.

$\mathrm{Y}$ esa frente hay que destrozarla; y ese seno hay que perforarlo; y ese vientre hay que agujerearlo a balazos.

Digo que es terrible.

En esta expresión, consejo de guerra, está la guerra; es decir, la muerte infligida al hombre por el hombre; no está la muerte infligida por el hombre a la mujer.

No trastoquemos los profundos instintos del hombre. Dejemos tranquilos a nuestros soldados. No les hagamos fusilar mujeres.

De acuerdo, se dice. Está la guillotina.

Esto es grave.

Digámoslo con total claridad, la guillotina se niega. La guillotina es una persona civil y no un funcionario militar; obedece a togas rojas, no a charreteras. No le importa matar, pero correctamente. Declina su competencia.

Continuemos.

¿Quién levantará el cadáver? ¿Quién se lo llevará? ¿Quién lo examinará? ¿Quién constatará miembro a miembro, una herida aquí, una fractura allá, el paso de la ley por este pobre cuerpo desafortunado? Aquí, se revuelve dentro de nosotros no se sabe qué formidable pudor, que es lo más grande que tiene la conciencia humana.

Y si la miserable no cae muerta, ¿quién le dará lo que se llama el golpe de gracia? Se imaginan al hombre cualquiera que este sea al que van a hacer que salga de las filas y al que le dirán: todavía vive, acabe con ella. ¿Qué crimen ha cometido ese hombre para que lo obliguen a hacer eso? ¿Con qué derecho añaden ustedes ese condenado a esa condenada? ¿Con qué cara mirará su mosquetón a partir de entonces? ¿Qué confianza podrá tener ese soldado en ese fusil? ¿Después de haber saltado la tapa de esos sesos, seguirá considerándolo idóneo para liberar la Alsacia y la Lorena de ustedes? ¿Podrá el verdugo volver a convertirse en héroe?

Tremendo dilema. Alternativa monstruosa.

Fusilar es legal, pero imposible.

Guillotinar es posible, pero ilegal.

¿Qué decisión tomar entonces?

Les voy a decir algo espantoso:

Conceder la gracia. ${ }^{3}$

3 Hugo, V., Écrits sur la peine de mort, Arles, Actes Sud, 1992 [1979], pp. 261-263 [Trad. cast. de Pozanco, V., Escritos sobre la pena de muerte, Barcelona, Editorial Ronsel, 2002, pp. 253-255]. Para la lectura que Derrida realiza de este texto véase: Derrida, J., Séminaire La peine de mort, vol. I, op. cit., p. 257 sq. [Trad. cast., p. 161 
La cuestión que se plantea, dice Hugo, es espantosa (effrayante). Pero no es la cuestión de la pena de muerte, no es la muerte la que es espantosa, sino el hecho de que esa pena de muerte, de que ese tipo de muerte se aplique a una mujer. Lo espantoso no reside en la pena de muerte sino en aquello que la vincula con la mujer. Para Hugo, por lo tanto, lo espantoso sería colocar a la mujer dentro de lo espantoso de la pena de muerte. La mujer revelaría lo espantoso dentro de lo espantoso, lo espantoso mismo. La figura de la mujer $-\mathrm{y}$ veremos que esta distinción entre mujer y figura sostiene el argumento- mostraría lo espantoso de lo espantoso, la espantosidad de lo espantoso, el corazón de lo espantoso de la pena de muerte al dar muerte a la figura del origen de la vida. Y esta espantosidad pura, esta esencia de lo espantoso dentro de lo espantoso, Hugo la utiliza para atacar a la pena de muerte, para poner de relieve lo espantoso, precisamente, de la pena de muerte. Cabe plantear si lo espantoso no aparece ya en Hugo como aquello que vendría a posibilitar la diferenciación entre la pena de muerte y lo espantoso de la pena de muerte.

Una mujer llamada...-¿qué importa el nombre?- Una mujer ha sido condenada a muerte.

Lo que parece importar en el argumento de Hugo no es la mujer que ha sido condenada a muerte, no es el artículo definido "la" el que capitanea la frase sino, por el contrario, el artículo indefinido "una" ("una mujer ha sido condenada a muerte"). Lo que importa es la figura de la mujer y no la mujer individual y concreta que ha sido condenada. La mujer, esa mujer única e irremplazable que ha sido condenada a muerte, representa a todas las mujeres. La mujer, esa mujer individual y determinada que va a ser ajusticiada es sustituida por todas las mujeres, por la figura de la mujer que representa, como en un teatro, a todas las mujeres. Es como si esa mujer fuera la madre que viene a proteger con su muerte a todas las mujeres. Protección efectuada a través de la boca de Hugo, boca de hombre con palabra en el lugar de la palabra, en el Parlamento, pues Hugo es miembro de la Asamblea constituyente de Francia en 1848 , donde defiende con su voz y con su voto "la abolición pura, simple y definitiva de la pena de muerte" 4 . Figura de mujer mártir, mujer bendita, "entre todas las mujeres", porque fue elegida por la palabra del hombre que la inmortaliza en sus Escritos sobre la pena de muerte. Hugo sería el ángel que anuncia que la palabra divina está en contra de la pena de muerte. Hugo sería el mensajero, el cartero de la verdad que anuncia, en contra de toda una historia de la Iglesia y del cristianismo, en contra pues de toda una historia de la verdad, que anuncia que la palabra divina dicta la abolición de la pena de muerte. Y para hacer coincidir la ley divina con la ley de los hombres, es necesario inscribir, según Hugo, en el primer artículo de la constitución la abolición de la pena de muerte. Y el argumento de lo espantoso, de aquello que va más allá de la crueldad misma de la pena de muerte y se vuelve espantoso, el argumento de lo espantoso que Hugo encuentra dentro de la pena de muerte, la espantosidad de lo espantoso, pues, consiste en denunciar que se ha condenado a muerte a una mujer. No obstante, para que ese argumento funcione contra toda la maquinaria de la pena de muerte, y no solamente contra la muerte individual de una mujer determinada, Hugo necesita sustituir a la mujer real por la

sq.].

4 Hugo, H., Écrits sur la peine de mort, op. cit., p.71 [Trad. cast. op. cit., p. 95].

$5 \quad$ La Biblia, Lucas 1: 42 
figura de la mujer, por una mujer que es todas las mujeres y que, por consiguiente, no es ninguna de ellas. Y la manera que Hugo elige para eliminar a esa mujer individual y convertirla en todas las mujeres es impedirle el nombre: "Una mujer llamada... -¿qué importa el nombre?- Una mujer ha sido condenada a muerte". Esa mujer que ya no es real, que ya no es solo real, simplemente real, igual que Jesús no era solo ni simplemente real cuando fue condenado a muerte por el Estado romano, esa mujer, pues, en el argumento de Hugo, y del mismo modo que Jesús, vendrá a salvar con su muerte a todas las mujeres, vendrá a salvar con su condena a muerte a todas las mujeres de la condena a muerte. Pero con una diferencia sustancial que consiste en que a ella no solo le han quitado la vida, sino también el nombre. Hay, por lo tanto, un doble robo, una doble privación. La mujer es privada de su vida y de su nombre. Pero el giro de la argumentación de Hugo consiste en utilizar el robo del nombre para salvar, o pretender salvar, no la vida concreta e individual de esa mujer condenada a muerte, de esa mujer sin nombre, sino la vida de todas las mujeres que la figura de esa mujer sin nombre representa. Entonces, más allá del claro objetivo de Hugo, ¿cuál sería esa lógica de robo y condena anónima? ¿Se puede condenar a alguien sin nombre? En efecto, la pena de muerte necesita un nombre propio. Solo se condena a individuos, de uno en uno; y esos individuos deben tener un nombre, una identificación que circunscriba sin lugar a dudas su persona jurídica. Por lo tanto, se condena siempre a un patronímico, a una denominación, a un apelativo, a un apellido, es decir, a una identidad igual a sí misma, a un individuo cuya identidad es solo suya, distinta de todas las demás identidades concretas. Y aquí la identidad va de la mano de la responsabilidad, pues la responsabilidad es del individuo. Y la irresponsabilidad para con la identidad, si eso fuese posible, se puede pagar con la vida, es decir, con la obligación de poner fin a esa identidad irresponsable. El nombre propio del individuo, aquel que se escribe en la sentencia judicial, permite la identificación plena del sujeto, permite la diferenciación total del sujeto identificado como culpable de cualquier otro sujeto, incluso de cualquier otro sujeto identificado legalmente con el mismo nombre, con los mismos nombres y apellidos, pues el nombre propio no es simplemente la letra ni su sonoridad, su grafía y sus fonemas, sino un sistema de apropiación que permite encerrar y aislar a aquello que atrapa con su palabra bajo una identificación plena e igual a sí, que permite identificar al sujeto, sujetar al sujeto a sí mismo; y que permite, finalmente, sujetar al sujeto condenado a su condena, ya sea mediante correas, cuerdas o cualquier otro sistema de sujeción establecido legalmente para administrar la muerte. Y cuando Hugo niega el nombre a la mujer, a esa figura de mujer que representa a todas las mujeres, lo cual también es una forma de negar el nombre a todas las mujeres, también está negando la identidad y la responsabilidad asociada a este. Hugo pondría así en juego una negación total de la mujer para salvarla. Sin embargo, ¿qué quedaría por salvar? La violencia del argumento de Hugo consistiría en encumbrar la figura de la mujer a cambio de la mujer, en salvaguardar su concepto a costa de suprimir aquello que lo sostiene y posibilita, es decir, la existencia individual y concreta, el nombre propio de esa mujer condenada a muerte que Hugo no puede mencionar para poner en juego su argumento crístico de redención.

Hugo utiliza esta diferenciación entre hombres y mujeres, que, según él, pertenece al orden social -"Fusilar a un hombre se entiende. De hombre a hombre esas cosas se hacen. Está dentro del orden, no dentro del orden natural sino del orden social"-, Hugo utiliza dicha diferenciación para intentar salvar a la mujer de lo espantoso 
de la pena de muerte, diciendo que lo propiamente espantoso, lo espantoso de lo espantoso, sería condenar a muerte a una mujer. Y al final de la cita, Hugo alude irónicamente a una tercera idea de lo espantoso (épouvantable) -"Les voy a decir algo espantoso: Conceder la gracia"- que podría volverse en su contra y convertirse en un espantoso intento de salvar al general e indeterminado "mujer" de lo espantoso de la pena de muerte.

Sin duda, el objetivo de Hugo es encomiable, pues se trata de salvar a todas las mujeres de la pena de muerte, de reducir en la medida de lo posible el apetito voraz de la guillotina. De todas formas, debemos insistir en esta diferencia fundamental entre mujer y figura de la mujer, en este tratamiento de la mujer y de la figura de la mujer, de la mujer como figura, porque por un lado sostiene el argumento y el objetivo de Hugo pero, por otro lado, y en el mismo gesto, profundiza en otro tipo de violencia, en una violencia sexual perversa. La perversidad consistiría en la necesidad de combatir la violencia de la pena de muerte con otra violencia, la sexual, indicando así subrepticiamente la necesidad de perpetuar la segunda violencia para poder combatir la primera. Y para asegurar el mantenimiento de la segunda violencia y propiciar la abolición de la primera es necesario inscribir el argumento con las excluyentes tintes del indeterminado y plural "mujeres"6. Tenemos aquí, por consiguiente, una perversa exclusión, una doble exclusión, la exclusión de la pena de muerte en nombre de otra exclusión.

Sin duda, no podemos perder de vista que esta lógica contradictoria de la exclusión, lógica compasiva y perversa, descansa sobre una interpretación simplista de la diferencia sexual. Todo indica que Hugo no tiene ninguna duda a la hora de diferenciar entre hombres y mujeres, parece tener claro cuál es el límite. Pero esta lógica de la exclusión fronteriza descansa sobre una lógica psicoanalítica de otra exclusión: la exclusión del pene, la exclusión de lo sin pene. Todo ocurre como si la pena de muerte solo debiera dar muerte al pene, al pene que es la autoridad, la virilidad del poder. Como un pene que da muerte a otro pene, que da la muerte al otro para erigirse o elevarse en cuanto pene que somete desde lo alto al otro. Y el reverso de esta lógica, reverso también incuestionado, es la lógica de la apropiación del pene. La apropiación del pene sería la apropiación del poder, de la vara de mando, del poder teológico sobre la vida y sobre la muerte. Teología fálica que sirve de base para decidir quién tiene pene y quién no, por lo tanto, teología que define la exclusión del pene y la sumisión de lo excluido. ¿Quién o qué está en condiciones de decidir quién tiene y quién no tiene pene? Contra esta teología falogocéntrica cabe poner de relieve el prejuicio y pensar el pene como un indecidible -como Derrida hace en Glas/Clamor - y, por lo tanto, deconstruir tanto la apropiación del poder como los sistemas de exclusión.

Si comparamos ahora la exclusión que pretende el abolicionista Victor Hugo,

$6 \quad$ Uso que recuerda a otro plural indeterminado menospreciado por la tradición, los animales, al que Derrida le dedica muchas páginas en L'animal que donc je suis, Paris, Galilée, 2006. Derrida habla del animal palabra, todos los animales que están reducidos a una palabra, que no son más que una palabra plural e indeterminada: animales, animaux, y que Derrida va a escribir, aprovechando la pronunciación francesa, animot, ("animote" según la traducción española de Cristina de Peretti y Cristina Rodríguez Marciel). La palabra "animales" supondría ya una violencia contra ellos en la reducción absoluta de su diferencia, en la eliminación total de su singularidad.

7 Derrida, J., Glas, Paris, Galilée, 1974 [Trad. cast. coordinada por Peretti, C., y Ferrero, L., Clamor/Glas, Madrid, La Oficina de Arte y Ediciones, 2015]. 
paternalista y profundamente cristiana, con la idea de un ferviente defensor de la pena de muerte como lo fue Kant, defensor de la pena de muerte en nombre de la pureza de la justicia y en nombre de la dignidad humana, si comparamos ambas argumentaciones podemos encontrar otra exclusión, otra exclusión perversa que quizá se encuentra en la base de toda la exclusión de la violencia sexual. En efecto, para Kant, hay algo que está por encima de la vida, algo que sobrepasa la vida y es más importante que la vida misma, algo que está por encima de la vida humana y que le otorga su sentido, a saber, la dignidad humana. No se trata simplemente de la vida, del mero proceso biológico de estar vivo, como sin duda lo está el ser humano, pero también los animales y las plantas, etc., no se trata simplemente de conservar la vida, sino de preservar y proteger aquello que hace que la vida merezca ser vivida para un ser moral, es decir, la dignidad de la vida, la dignidad del ser humano que merece una vida digna. Este espirituoso gesto kantiano abre una posibilidad quizá desalmada, puesto que colocar la dignidad de la vida por encima de la vida supone la posibilidad de prescindir de la vida para conservar la dignidad. De este modo, la justicia no trabajaría tanto en favor de la vida como en favor de la dignidad de la vida. Y como, según Kant, solo un ser moral posee esa dignidad, entonces la justicia se preocuparía por salvaguardar la dignidad del ser humano que hace al ser humano. Dicho de otra forma, protegiendo la dignidad del ser humano se protege al ser humano, y no al revés. La fórmula consiste, pues, en proteger al ser humano con algo que, ciertamente, está en su interior y le pertenece, pero que, al mismo tiempo, lo excede; algo, la dignidad, que está a la vez dentro y fuera del ser humano, y que, debido a esta ubicuidad, puede, debe, en ocasiones, prescindir del ser humano para asegurar su existencia: autoinmunidad de la dignidad a través del sistema jurídico de la pena de muerte. En ocasiones se debe prescindir de la existencia de un individuo concreto, y por lo tanto también de la dignidad intrínseca a ese ser moral, para proteger a la dignidad misma y proteger así al ser humano. Esta es la idea que Kant parece defender cuando cita la máxima farisaica: "Más vale la muerte de un hombre que la corrupción de todo un pueblo", en su Metafísica de las costumbres. Cabe recordar que la figura de la dignidad en Kant es jurídicamente crucial pues se opone a la idea de precio y permite distinguir entre medios y fines.

En el reino de los fines todo tiene o un precio o una dignidad. Aquello que tiene precio puede ser sustituido por algo equivalente; en cambio, lo que se halla por encima de todo precio y, por tanto, no admite nada equivalente, eso tiene una dignidad. Lo que se refiere a las inclinaciones y necesidades del hombre tiene un precio comercial; lo que, sin suponer una necesidad, se conforma a cierto gusto, es decir, a una satisfacción producida por el simple juego, sin fin alguno, de nuestras facultades, tiene un precio de afecto; pero aquello que constituye la condición para que algo sea fin en sí mismo, eso no tiene meramente valor relativo o precio sino un valor interno, esto es, dignidad. ${ }^{9}$

El ser humano es un fin en sí mismo y no un medio, ese es el contenido fundamental del imperativo categórico kantiano. Célebre aserto que dicta obrar del tal modo que

8 Kant, I., Metaphisik der Sitten, 1797, p. 332 [Trad. cast. de Cortina, A., y Conill, J., La metafisica de las costumbres, Madrid, Tecnos, 1989, p. 167].

$9 \quad$ Kant, I., Grundlegung zur Metaphysik der Sitten. Riga, (1785), 4:434 - 4:435. [Trad. de García Morente, M., Fundamentación de la metafísica de las costumbres, Edición de Pedro M. Rosario Barbosa, Primera Edición, San Juan, Puerto Rico, 2007, pp. 47-48.) 
se utilice la humanidad, tanto en la propia persona como en la persona de cualquier otro, siempre al mismo tiempo como un fin y nunca solamente como medio, es decir, que no se puede poner precio al ser humano pues de hacerlo se estaría negando la dignidad intrínseca del mismo. Por consiguiente, no se puede poner precio a su cabeza, por así decirlo. En este sentido la pena de muerte no puede ser el precio que hay que pagar por lo que Kant denomina un homicidium dolosum, y que distingue del homicidium sin más, pues poner precio al ser humano significaría cosificarlo y negarle, por consiguiente, su dignidad. La pena de muerte, por lo tanto, no puede ser ejemplar, pues no se puede usar al ser humano como medio para conseguir un fin, incluso si ese fin consistiese en que los seres humanos (fines en sí mismos) no matasen a otros seres humanos (a otros fines en sí mismos). La pena de muerte no es el precio que hay que pagar, sino la aplicación estricta del deber moral que debe salvaguardar la dignidad de la vida humana por encima, incluso, de la vida humana. Y la dignidad no se pierde en la aplicación del castigo que elimina a un condenado porque semejante dignidad consiste precisamente en ser digno de ese castigo. El ser humano se dignifica en el acceso a la justicia, en el sometimiento a las leyes y al deber, a la moralidad que le pertenece y lo constituye a la vez que lo excede. De tal modo que la dignidad del ser humano no se negaría con el fin de la vida del sujeto condenado sino con la negación del acceso al sistema jurídico $\mathrm{y}$, por lo tanto, al castigo. Un ser humano sin dignidad, sin acceso a la dignidad de la justicia, no sería más que un ser vivo, solo un ser vivo, como los animales o las plantas. $\mathrm{O}$ al menos eso piensa Kant.

Si ahora enfrentamos el argumento abolicionista de Hugo, que tenía por objetivo liberar a las mujeres de lo espantoso de la pena de muerte, pero con el objetivo de fondo de luchar a favor del abolicionismo mediante el mantenimiento de la exclusión de la mujer, si trasladamos esta lógica contradictoria de Hugo a la lógica anti-abolicionista kantiana, Kant reprocharía a Hugo que esa exclusión del sistema del castigo penal es en realidad la negación de la dignidad de la persona humana. Es decir, la negación de la dignidad de la mujer que ni siquiera sería digna de castigo. La exclusión de la responsabilidad penal que busca estratégicamente Hugo significaría, en términos kantianos, la negación del deber moral, y por lo tanto de la autonomía que constituye la dignidad del ser humano y su naturaleza misma, como la define Kant en la Fundamentación de la metafísica de las costumbres: "La autonomía, es, pues, el fundamento de la dignidad de la naturaleza humana y de toda naturaleza racional" ${ }^{10}$. En cambio, Kant reconocería cierta lógica ventajosa en el argumento de Hugo, pues si este pretende liberar a las mujeres de la responsabilidad penal negándole el nombre, según la lógica jurídica kantiana, esa mujer no sería imputable porque se convertiría en cosa, en algo que no tiene nombre propio sino nombre común, en algo que, precisamente por ser algo, no es susceptible de imputación: "Persona es el sujeto cuyas acciones son imputables (...) Una cosa es algo que no es susceptible de imputación" "11. Por lo tanto, en esta acumulación de violencias, y aunque la exclusión benévola que pretende Hugo sería para Kant un argumento en parte eficaz, también representaría una exclusión radical y general que posibilitaría

10 Kant, I., Grundlegung zur Metaphysik der Sitten. Riga, (1785), 4:436 [Trad. cast., Fundamentación de la metafísica de las costumbres. 1996., México, Porrúa., 49].

11 Immanuel Kant, Metaphisik der Sitten, 1797, p. 223 [Trad. cast., La metafisica de las costumbres. Madrid, Tecnos, 1989, 30 p. 30]. 
la historia de las exclusiones singulares de las mujeres de los sistemas tradicionales de los hombres, incluso de la humanidad del hombre, de lo propio del hombre. El argumento consistiría en concluir que lo propio de la mujer sería no pertenecer a lo propio del hombre. Dicho de otra forma, aquello que para el profundo cristianismo de Hugo significaría la salvación de la mujer, para el profundo cristianismo de Kant, por el contrario, significaría la condenación de la mujer. Cuando en realidad parece que todo sucede al revés, es decir, que Hugo la condena al pretender salvarla y que Kant pretende salvarla condenándola. Pero ninguno ofrece una postura que permita excluir la exclusión, que permita luchar a la vez contra la violencia sexual y contra la pena de muerte como lo propio del hombre. Quizá porque la solución no podría pasar simplemente por la inclusión sino, antes bien, por repensar y rehacer el conjunto del sistema que da cabida a la exclusión misma. Dicho de otra forma, ni dar ni quitar simplemente acceso al mundo de los hombres sino reconfigurar por completo ese mundo y ese concepto de hombre y de propio del hombre que está en la base de la violencia. En definitiva, activar la deconstrucción del hombre, la deconstrucción de lo propio del hombre. 